\title{
Walls Block Waves: Using an Inundation Metaphor of Immigration Predicts Support for a Border Wall
}

\author{
Tyler Jimenez ${ }^{1}$, Jamie Arndt ${ }^{1}$, Mark J. Landau ${ }^{2}$
}

[1] Department of Psychological Sciences, University of Missouri, Columbia, MO, USA. [2] Department of Psychology, University of Kansas, Lawrence, KS, USA.

Journal of Social and Political Psychology, 2021, Vol. 9(1), 159-171, https://doi.org/10.5964/jspp.6383

Received: 2020-04-15 • Accepted: 2021-03-10 • Published (VoR): 2021-04-20

Handling Editor: Lucas A. Keefer, University of Southern Mississippi, MS, Hattiesburg, USA

Corresponding Author: Tyler Jimenez, Department of Psychological Sciences, 210 McAlester Hall, Columbia, MO 65211, USA. E-mail:

tylerjimenez@mail.missouri.edu

Supplementary Materials: Data, Materials [see Index of Supplementary Materials]

\begin{abstract}
From early 20th century headlines to presidential tweets, immigration is described frequently in terms of waves, floods, and tides. Although usage of this inundation metaphor has been widely documented, its potential influence on immigration attitudes has not been assessed empirically. Building from conceptual metaphor theory's claim that abstract ideas can be grounded in simpler, concrete concepts, we hypothesized that using the inundation metaphor to understand immigration contributes to support for a U.S.-Mexico border wall as a figurative means to block immigrants. Accordingly, social media posts supporting a border wall contained more inundation-metaphoric expressions than messages opposing a wall and messages opposing immigration without reference to a wall (Study 1; $\mathrm{N}=4$,067). Converging experimental tests show, when controlling for political attitudes, exposure to the inundation metaphor increases support for a border wall (Studies $2 \mathrm{a}$ and $2 \mathrm{~b} ; \mathrm{N}=737$ ). These findings add to the growing body of evidence that political cognition and policy attitudes are partly motivated by metaphoric comparisons to concrete ideas that are irrelevant in a literal sense.
\end{abstract}

\section{Keywords}

political psychology, conceptual metaphor, immigration, social media, border wall, inundation metaphor

Immigration is a "tidal river of labor, of homeless peasantry, surging in, surging out...like a massive sheet of water over a dam," wrote a 1923 Saturday Evening Post columnist (cited in O’Brien, 2003). Nearly a century later, a headline on nbcnews.com claimed a "record number of undocumented immigrants flooded the southern border" (Ainsley, 2019). As these statements demonstrate, immigration discourse often relies on an inundation metaphor that compares immigrants to water and their perceived impact on one's country to dangerous flooding. A discourse analysis of newspaper articles found widespread use of the inundation metaphor (Santa Ana, 1999), and politicians such as President Trump frequently describe immigrants as "pouring in," "flooding across borders," and coming in "waves." This metaphor is not unique to American immigration discourse, having been used to describe immigrants, refugees, and asylum seekers in England (Charteris-Black, 2006), Italy (El Refaie, 2001), and Germany (Böke, 1997).

The metaphors used to describe immigrants may influence how people judge the effectiveness of immigration policies. Indeed, the aforementioned qualitative analyses propose that the inundation metaphor fuels support for restrictive anti-immigration measures (e.g., Charteris-Black, 2006; O’Brien, 2003; Santa Ana, 1999). Still, to our knowledge this claim has not been assessed empirically. To fill this gap, we build from conceptual metaphor theory (Lakoff \& Johnson, 1980), which explains salient metaphors motivate reasoning about abstract problems using the logic of concrete ideas 
that are easier to conceptualize. If the inundation metaphor shapes how people understand immigration, and not just how they talk about it, then we expect it to orient people toward immigration policies akin to familiar solutions to dangerous flooding, despite the fact that these scenarios are unrelated superficially. Because walls are commonly understood to block flooding water, we expect usage of the inundation metaphor to predict, and exposure to this metaphor to increase, support for a wall on the U.S. southern border. We report correlational tests of this hypothesis in the context of social media posts as well as experimental tests that manipulate the salience of the inundation metaphor.

As background, conceptual metaphor theory posits that metaphor is a cognitive tool that people can use to understand one concept-called the target-in terms of a superficially dissimilar concept-called the source-that is relatively easier to grasp. Metaphor use facilitates understanding by providing a mental mapping between elements of the source and analogous elements of the target. Thinking with metaphor transfers knowledge of the source-what it is like, how it relates to other things-as a template for reasoning about and acting upon the target.

Conceptual metaphor theory has inspired detailed qualitative analyses showing that political discourse is saturated with metaphors (e.g., Charteris-Black, 2011; Hanne et al., 2014; Musolff \& Zinken, 2009). They are used in editorials, speeches, and other outlets to communicate about terrorism (Kruglanski et al., 2007), negotiation (Gelfand \& McCusker, 2002), immigration (O’Brien, 2003), gender in business (Koller, 2004), abortion (Coulson, 2006), and war (Lakoff, 1991), among other social issues. Beyond documenting metaphors' ubiquity, these analyses show metaphor use correlates with patterns in political communication in ways that suggest that people conceptualize societal issues at least partly in terms of dissimilar, more concrete concepts.

Converging support for metaphor's role in shaping political cognition comes from experimental tests. A common paradigm for testing metaphoric influences on cognition is to expose some people to a metaphoric framing-a message that uses words or images to compare a target to a source. Others receive an equivalent message framing the same target in literal terms or using an alternative metaphor. Researchers reason that if exposure to a metaphoric framing activates a conceptual mapping, then it should lead people to process the target in ways that correspond systematically to their knowledge of the metaphor's source (Landau et al., 2010).

Several studies show activating metaphors in this manner influences political cognition (Landau, 2017). For example, participants who read an article comparing a city's crime problem to an aggressive beast recommended punitive crime-reduction strategies, whereas those who read the same facts framed in disease-metaphoric terms recommended strategies addressing crime's root causes (Thibodeau \& Boroditsky, 2011). The messages did not mention crime reduction strategies, suggesting that exposure to a metaphoric framing prompted participants to transfer knowledge of a salient source to generate solutions to a problem in a different domain.

Related studies show exposure to a metaphoric framing influences how people evaluate solutions to abstract problems (e.g., Thibodeau et al., 2019). Specifically, when a message frames a target problem metaphorically in terms of a source problem, people prefer solutions to the target problem that are appropriate for addressing the source problem, even though the two problem scenarios are superficially unrelated and may require different approaches. For example, after reading a health message that framed depression (the target problem) metaphorically in terms of being physically low or sunken (e.g., feeling low), people preferred an anti-depressant medication framed metaphorically as elevating ("lifts you up") compared to an equivalent medication framed in literal terms (Keefer et al., 2014). Such findings suggest metaphor use motivates reliance on commonsense understandings of the metaphor's source to evaluate potential solutions to an abstract problem.

Using converging correlational and experimental methods, this work is part of a growing body of research demonstrating the power of metaphor to shape political thought and communication across a range of issues. Recent work summarizes this literature and explicates underlying mechanisms that are involved in this process (Burgers et al., 2016; Keefer \& Landau, 2016; Thibodeau et al., 2017, 2019).

The current research extends these findings to examine the role of the inundation metaphor in attitudes toward a wall on the U.S.-Mexico border. Although many Americans favor border security, there is strong disagreement over the effectiveness of a wall, so much so that President Trump declared a national emergency to fund the wall without Congress' approval (Baker, 2019). Many believe that a border barrier would effectively block border crossings. Opponents point out that a wall needs constant guarding, that official ports of entry are the main route for drugs and 
human trafficking, and that a wall can foment hostility. Psychological factors are likely to contribute to the appeal of both positions.

We examine whether support for the wall is motivated by the inundation metaphor, at least in part. If people represent immigrants metaphorically as waves of rushing, destructive water, then a physical barrier may appear to be an effective solution to "block" immigrants' entry. If immigrants are instead represented without metaphor, then a wall may seem less effective. Of course, support for a border wall is likely to be strongly predicted by pre-existing political ideologies, especially conservatism and support for President Trump. Still, we test the possibility that situational factors - such as exposure to the inundation metaphor - may, at least temporarily, influence border wall attitudes when controlling for political ideology.

\section{Overview of Studies}

Two studies examined the relationship between the inundation metaphor and support for a border wall. Study 1 examined this relationship in social media discourse by comparing the prevalence of inundation-metaphoric expressions among various types of immigration-related messages. The current analysis predicts tweets expressing support for a border wall will contain more inundation-metaphoric expressions of immigration than tweets expressing anti-border wall sentiment or anti-immigrant sentiment without mention of a border wall. Although Study 1's method informs the link between spontaneous metaphor use and border wall support in naturalistic language, it does not permit causal inference. Study 2 attempts to establish causality by manipulating exposure to an inundation-metaphoric framing of immigration and testing its effect on border wall support. All study materials, coding details, and deidentified data, can be found on OSF (see Supplementary Material).

\section{Study 1}

Study 1 used observational methods to examine the association between inundation metaphor use and border wall support. We collected immigration-related tweets and coded them for the presence of inundation-metaphoric expressions. If use of the inundation metaphor facilitates border wall support, then pro-border wall tweets should contain more inundation-metaphoric expressions than anti-border wall tweets and anti-immigration tweets without mention of a border wall.

\section{Method}

Twitter is a social media platform on which users post $t w e e t s$, brief text messages limited to 280 characters. As politics is among the most popular topics on Twitter (Lee et al., 2011), the site provides opportunities to gain valuable insights into language use in political discussions. Through their application programming interfaces (APIs), Twitter makes tweets publicly available for researchers. We used the R package $r$ tweet (Kearney, 2016) to retrieve tweets based on the presence of requested keywords through Twitter's APIs.

We compared the prevalence of the inundation metaphor among three types of expressions: (1) anti-immigrant and pro-border wall, (2) anti-immigrant without mention of border wall, and (3) anti-border wall. Hashtags (e.g., \#BuildTheWall) are commonly included in tweets to signify a theme or topic. We used hashtagify.com-a commonly used site documenting the popularity of hashtags used on Twitter (Cavazos-Rehg et al., 2019; Grover et al., 2019)-to select hashtags for identifying tweets in each of these categories. Three hashtags of similar popularity were found which corresponded to the expressions of interest: (1) \#BuildTheWall; (2) \#DeportThemAll; and (3) \#NoWall (Table 1 summarizes the immigration expression categories and their corresponding hashtags). 


\section{Table 1}

Categories of Immigration-Related Expressions

\begin{tabular}{ll}
\hline Type of Expression & Operationalization \\
\hline Anti-immigrant, pro-border wall & Tweet tagged with \#buildthewall \\
Anti-immigrant, no mention of border wall & Tweet tagged with \#deportthemall (and without the word “wall”) \\
Anti-border wall & Tweet tagged with \#nowall \\
\hline
\end{tabular}

The hashtag \#BuildTheWall is used to indicate support for the proposed border wall between the U.S. and Mexico. For example, one user included this hashtag after writing:

"If we were to go by @RepHankJohnson logic, the \#USA should sink with all the illegal immigrants piling into it which would cause it to flood. \#BuildTheWall”

\#DeportThemAll was used on similarly anti-immigrant tweets, though without mentioning a border wall. One sample tweet from this category is:

"Weaponizing the census? Well if they are here legally they have nothing to worry about. If they're not here legally then they should be gone anyway \#DeportThemAll"

The hashtag \#NoWall was used in opposition to the border wall. It accompanied statements such as:

"No Democrat is asking for open borders. We're asking for common sense and common decency. If you believe we can spend trillions of dollars on endless wars in foreign countries but we can’t afford to help those closest to us, then what does that say about America? \#NoWall"

We collected a total of 4,067 tweets tagged with \#BuildTheWall $(n=1,386)$, \#DeportThemAll $(n=1,351)$, or \#NoWall ( $n$ $=1,330$ ), excluding tweets tagged with more than one of these hashtags (e.g., tweets tagged with \#BuildTheWall and \#DeportThemAll). This sample size was based on the number of recent tweets available through Twitter's API.

To measure the frequency of inundation-metaphoric expressions, we created a specialized dictionary using a text analysis program called the Linguistic Inquiry and Word Count (LIWC; Pennebaker, Booth, \& Francis, 2007). Metaphorical terms such as "flood" and "wave" were included in the dictionary based on previous research on the inundation metaphor (Charteris-Black, 2006; Lederer, 2013; O’Brien, 2003; Strom \& Alcock, 2017). Appendix A lists the dictionary of inundation-metaphoric terms.

\section{Results}

The sample of tweets was analyzed with LIWC using the previously described dictionary. As the metaphoric terms included in the LIWC dictionary also have literal meanings which can be used outside of the context of immigration, tweets that the LIWC analysis indicated contained an inundation metaphor were inspected to ensure that the term was used metaphorically. LIWC analyses return a percentage of words from the sample that are included in its dictionary. Thus, for each tweet, its returned LIWC score is dependent on (1) the presence of an inundation-metaphoric term and (2) the length of the tweet. To avoid bias due to differences in tweet length, we computed a new variable in which tweets expressing the inundation metaphor were scored as " 1 " and tweets not expressing the inundation metaphor were scored as " 0 ".

As no tweets tagged with \#NoWall contained an inundation metaphor, and thus there was no variability in this condition, we focused on inundation-metaphoric expressions in the \#BuildTheWall and \#DeportThemAll conditions. A chi-square test demonstrated, as predicted, tweets tagged with \#BuildTheWall were more likely to contain inundation-metaphoric expressions than those tagged with \#DeportThemAll, $\chi^{2}(1, N=2,737)=9.19, p=.002$. In raw numbers, 
0\% of tweets tagged with \#NoWall contained an inundation metaphor, $0.60 \%$ of tweets tagged with \#DeportThemAll contained an inundation metaphor, and $1.91 \%$ of tweets tagged with \#BuildTheWall expressed the inundation metaphor.

\section{Discussion}

Study 1 offers preliminary support of the association between use of the inundation metaphor and border wall support in naturalistic discourse. Social media posts expressing support for the border wall were more likely to feature inundation-metaphoric expressions than were posts that opposed a border wall and, critically, posts that opposed immigration without mentioning a border wall. Posts opposing the border wall did not express the inundation metaphor, which is consistent with previous analyses of this metaphor suggesting it is only used to express anti-immigrant sentiment (Santa Ana, 1999).

Although the methodology used in Study 1 offers insights into the usage of the inundation metaphor in common discourse, its cross-sectional nature precludes causal inference. The inundation metaphor may not necessarily influence border wall attitudes, but rather may be used by people who already support a border wall. Study 2 was designed to address the possibility that exposure to the inundation metaphor has a causal effect on border wall support.

\section{Study 2}

Study 2 used experimental methods to test a potential causal relationship between exposure to the inundation metaphor and border wall support. Given the salience of border wall discourse during the government shutdown in early 2019, Studies 2a and 2b were conducted between late-January and mid-February. Study 2a tested whether the inundation metaphor would increase border wall support; Study $2 \mathrm{~b}$ was intended to increase the sample size and replicate Study $2 \mathrm{a}$.

\section{Study $2 a$}

\section{Method}

Design and procedure - After providing consent, participants completed a measure of social desirability. They were then randomly assigned to read an ostensible opinion piece on immigration that described immigrants in either literal or inundation-metaphoric terms. As the experimental manipulation consisted of subtle words and phrasing, it was important that participants paid careful attention to its contents. To motivate careful reading, participants were instructed they would be asked questions about its contents later in the study. Participants were next asked to indicate their level of border wall support and demographic information before being debriefed.

Participants - American participants $(N=534)$ were recruited from Amazon's Mturk using TurkPrime (Litman et al., 2017). Because many researchers have observed a recent decline in Mturk data quality (Chmielewski \& Kucker, 2020), we included an attention check, which has been shown to improve data quality (Barends \& de Vries, 2019). In the immigration passages, it was noted that the unemployment rate was $5 \%$. After reading this passage, participants were asked to recall the unemployment rate. We excluded from analyses participants who failed to answer this question correctly as well as those who did not complete the dependent measure $(n=171)$, leaving a final sample of 363 participants. Excluded participants did not differ by condition in either Study 2a or $2 \mathrm{~b}$. The racial (81.3\% White), gender ( $57.9 \%$ female), and age $(18-83, M=38.58, S D=12.91)$ breakdown of the sample was consistent with broader Mturk demographics (Litman \& Robinson, 2020). This initial sample size was based on available funds. We return to the issue of sample size and power in the Discussion of Study 2a.

Materials - All materials presented are listed below in their respective order.

Social desirability. A measurement of the tendency to answer survey questions in socially desirable ways was included as a filler measure. This measurement consists of 11 true-or-false questions $(\alpha=.75)$ such as "I'm always willing to admit when I've made a mistake" (Crowne \& Marlowe, 1960). Social desirability did not moderate effects in either study. 
Inundation metaphor manipulation. Participants were randomly assigned to read a passage framing undocumented immigrants in either inundation-metaphoric terms or equivalent literal terms (included in Appendix B). The passage was presented as an opinion piece, and participants were told to read carefully as they would later answer questions about it. Each passage portrayed the U.S. economy as relatively weak and argued that this can be partially blamed on undocumented immigrants. The only differences between the literal and metaphoric passages were small changes to the wording used to describe undocumented immigrants. In the literal passage, undocumented immigrants were described without the use of a consistent provided metaphor. In the inundation-metaphoric condition, undocumented immigrants were described using common expressions of the inundation metaphor. For example, the literal passage argued that "immigrants come into our nation," while the corresponding claim in the metaphor passage was "immigrants flood into our nation."

One possibility worth considering is that the materials used in the inundation metaphor condition may also increase the perceived severity of immigration. Thus, if the hypothesized pattern emerges, it would be possible that border wall attitudes are not related to the inundation metaphor per se, but rather to perceptions of immigration quantity. In a pilot study we examined this possibility empirically, recruiting 302 participants to read either the inundation-metaphoric framing or the literal framing of immigration. After, they were asked, "Based on what you just read...to what extent is illegal immigration a problem?”, “... what are your feelings toward illegal immigrants?”, and “... how many illegal immigrants do you think cross the U.S.-Mexico border each day?" Responses to these items did not differ by condition (all ps > .23). It does not appear that the two manipulations differed in depicted severity of immigration.

Border wall support. We created three face-valid items measuring border wall support: "How much do you support the building of a border wall? To what extent will a border wall deter illegal immigration? How safe would a border wall make you feel?" Responses were made on a 7-point scale $(1=$ not at all; 7 = very $m u c h)$ and showed high internal reliability $(\alpha=.95)$.

Demographics. Typical demographic questions (e.g., race, gender, and age) were assessed as well as extra questions related to political attitudes. These included political conservatism (measured on a scale of 1 [very liberal] to 7 [very conservative]), political party affiliation, 2016 voting behavior, and whether Trump should be re-elected in 2020 (measured on a scale of 1 [absolutely not] to 5 [absolutely]).

\section{Results}

Preliminary analyses - Bivariate correlations between study variables were explored and are presented in Table 2. Given that support for President Trump and political conservatism were both significantly positively correlated with border wall support, it was tested whether these variables differed by experimental condition. No differences were found for Trump support, $F(1,361)=0.57, p=.45, \eta^{2}=.002$ or political conservatism, $F(1,361)=1.00, p=.32, \eta^{2}=.003$.

\section{Table 2}

Bivariate Correlations Between Study $2 a$ Variables

\begin{tabular}{|c|c|c|c|c|}
\hline Variable & 1 & 2 & 3 & 4 \\
\hline 1. Social Desirability & - & -.07 & -.08 & -.04 \\
\hline 2. Trump support & & - & $.72^{* *}$ & $.84^{* *}$ \\
\hline 3. Conservatism & & & - & $.65^{* *}$ \\
\hline 4. Border wall support & & & & - \\
\hline
\end{tabular}

Note. Variables are listed in order of appearance.

${ }^{*} p<.05 .{ }^{* *} p<.01$.

Main analyses - To test whether exposure to the inundation metaphor would increase border wall support, a one-way ANOVA tested the effect of condition on wall support. This effect was not significant, $F(1,356)=2.60, p=.11, \eta^{2}=.01$, though was in the predicted direction. Those in the metaphor condition indicated directionally higher support for a border wall $(M=3.20, S D=2.12)$ than those in the literal condition $(M=2.85, S D=2.00)$. 
Because border wall support was predicted by political conservatism and Trump support, we then tested whether controlling for these variables would change the effect of condition. When controlling for political conservatism and Trump support, the effect of condition on border wall support was strengthened, $F(1,354)=3.06, p=.08, \eta^{2}=.01$. Inspection of the means shows that participants exposed to the inundation-metaphoric framing of immigration reported marginally higher border wall support $(M=3.13, S E=0.08)$ than participants exposed to the literal immigration framing $(M=2.93, S E=0.09)$.

\section{Discussion}

Study 2a tested whether exposure to the inundation metaphor would increase support for building a border wall between the U.S. and Mexico. The results were directionally consistent with this hypothesis, though not at a significant level. Those in the metaphor condition indicated somewhat higher support for the wall than those in literal condition. This effect was strengthened by controlling for political conservatism and Trump support, though it remained only marginally significant.

For a number of reasons, a direct replication of Study 2a was performed. First, as it was not initially hypothesized that controlling for political conservatism and Trump support would strengthen the effect of condition on wall support, we were interested in whether this finding would replicate in a second study. Second, as the effect size indicates a relatively small effect of condition, it is possible that the sample was not large enough to reveal a significant effect. Indeed, a sensitivity power analysis ( $\alpha=.05, N=363$, numerator $d f=1$, number of groups $=2$, number of covariates $=2$ ) revealed that Study 2a provided $80 \%$ power to detect an effect of $f=.15$, whereas the observed effect was $f=.10$. Thus, Study $2 \mathrm{~b}$ can serve as a replication and expansion of the sample collected in Study $2 \mathrm{a}$.

\section{Study $2 b$}

\section{Method}

Design and procedure - The procedure and materials were identical to those of Study $2 \mathrm{a}$.

Participants - A total of 548 participants were recruited from Mturk. After applying the same exclusion criteria as in Study 2a, the final sample consisted of 374. The demographics were similar to those of the previous study, with the sample majority White (84\%), female $(60.4 \%)$, and between the ages of 18 and $81(M=43.12, S D=14.23)$. Using TurkPrime, we assured no participants from Study 2a were recruited in Study $2 \mathrm{~b}$.

\section{Results}

Preliminary analyses - As in Study 2a, we first explored bivariate correlations between study variables (presented in Table 3).

Table 3

Bivariate Correlations Between Study $2 b$ Variables

\begin{tabular}{lcccc}
\hline Variable & $\mathbf{1}$ & $\mathbf{2}$ & $\mathbf{3}$ & $\mathbf{4}$ \\
\hline 1. Social Desirability & - & $.13^{*}$ & $.12^{*}$ & .09 \\
2. Trump support & & - & $.73^{* *}$ & $.84^{* *}$ \\
3. Conservatism & & & - & $.70^{* *}$ \\
4. Border wall support & & & & - \\
\hline
\end{tabular}

Note. Variables are listed in order of appearance.

${ }^{*} p<.05 .{ }^{* *} p<.01$.

Next, we tested whether political conservatism and Trump support differed by condition. We detected a significant effect on Trump support, $F(1,371)=4.92, p=.03, \eta^{2}=.01$, with those in the literal condition expressing greater support 
$(M=2.38, S D=1.59)$ than those in the metaphor condition $(M=2.03, S D=1.46)$. A similar pattern emerged for political conservatism, though not at a significant level, $F(1,372)=2.80, p=.10, \eta^{2}=.01$. Those in the literal condition were somewhat more conservative $(M=3.91, S D=1.84)$ than those in the metaphor condition $(M=3.61, S D=1.65)$.

Main analyses - First, we tested whether border wall support differed between condition; no effect emerged, $F(1,370)$ $=0.53, p=.47, \eta^{2}=.001$. Next, attempting to replicate the results of Study 2a, we entered political conservatism and Trump support into the model as covariates. This returned a significant effect of condition on wall support, $F(1,367)=$ $4.48, p=.04, \eta^{2}=.01$. Specifically, those in the inundation metaphor condition indicated higher border wall support $(M=$ $3.32, S E=0.08)$ than those in the literal condition $(M=3.08, S E=0.08)$.

\section{Discussion}

Replicating the results of Study 2a, when controlling for political conservatism and Trump support, exposure to the inundation metaphor led to higher border wall support than exposure to an equivalent anti-immigration message framed without a provided metaphor. It should be noted that, without controlling for Trump support and political conservatism, the effect sizes of condition on border wall support varied between studies. It is possible that the unequal distribution of conservatism between conditions in Study $2 \mathrm{~b}$ can explain this discrepancy. Next, we looked across both studies to see whether this effect was observed within the total sample.

\section{Studies $2 a$ and $2 b$}

\section{Results}

Preliminary analyses - A 2 (framing condition: inundation metaphor vs. literal) x 2 (study: 2a vs. 2b) ANOVA was conducted to test for main and interactive effects of condition and study on support for the border wall. Although neither condition nor study revealed a main effect (both $p s>.28$ ), a marginally significant interaction emerged $F(1$, $726)=2.76, p=.10, \eta^{2}=.004$. As described in the previous Results sections, when not controlling for political attitudes, framing condition had a marginal effect in Study 2a and no effect in Study 2b. However, when controlling for political conservatism and Trump support, the interaction disappears $F(1,723)=0.07, p=.78, \eta^{2}<.001$. Bivariate correlations between study variables across both studies are presented in Table 4.

Table 4

Bivariate Correlations Between Variables Across Studies $2 a$ and $2 b$

\begin{tabular}{|c|c|c|c|c|}
\hline Variable & 1 & 2 & 3 & 4 \\
\hline 1. Social Desirability & - & .03 & .02 & .03 \\
\hline 2. Trump support & & - & $.72^{* *}$ & $.84^{* *}$ \\
\hline 3. Conservatism & & & - & $.68^{* *}$ \\
\hline 4. Border wall support & & & & - \\
\hline
\end{tabular}

Note. Variables are listed in order of appearance.

${ }^{*} p<.05 .{ }^{* *} p<.01$.

Main analyses - First, the effect of condition on wall support was tested using a one-way ANOVA; no effect emerged, $F(1,728)=0.32, p=.57, \eta^{2}<.001$. However, a significant effect was shown when controlling for political conservatism and Trump support, $F(1,725)=7.23, p=.01, \eta^{2}=.01$. Border wall support was higher in the inundation metaphor condition $(M=3.22, S E=0.06)$ than in the literal condition $(M=3.01, S E=0.06)$.

The present analysis treats political conservatism and Trump support as covariates to estimate the effect of inundation metaphor exposure on border wall support independent of pre-existing political ideology. However, one could also ask whether the effect of exposure to an inundation metaphor on support for the border wall was moderated by pre-existing political ideology. No support for this possibility was found. Specifically, there was no interaction between 
experimental condition and political conservatism, $b=-0.02, S E_{\mathrm{b}}=0.06, t(726)=-0.38, p=.70,95 \% \mathrm{CI}[-0.15,0.11]$, or Trump support, $b=0.06, S E_{\mathrm{b}}=0.05, t(725)=1.20, p=.23,95 \% \mathrm{CI}[-0.04,0.17]$.

\section{Discussion}

Studies $2 \mathrm{a}$ and $2 \mathrm{~b}$ supported the hypothesis that exposure to the inundation metaphor would increase support for a border wall between the U.S. and Mexico. In Study 2a, a marginal effect emerged after controlling for support for President Trump and political conservatism. As the necessity of these covariates was not specifically hypothesized, and the marginal effect was small, Study $2 \mathrm{~b}$ served as a replication and extension of Study 2a. Across both studies, when controlling for Trump support and political conservatism, support for the border wall was higher among those who previously read about immigrants described using the inundation metaphor than those who read a literal description of immigrants. Together, Studies $2 \mathrm{a}$ and $2 \mathrm{~b}$ achieved adequate power for detecting an effect size of $f=.10$.

\section{General Discussion}

Whether by waves, floods, or tides, immigration is often metaphorically compared to water. Building from conceptual metaphor theory, we hypothesized using this inundation metaphor would transfer information from the source (i.e., dangerous flooding) to the target (i.e., immigration) and affect subsequent attitudes toward immigration. As incoming flood water is often stopped with walls - be they dams, dykes, or levees - the inundation metaphor should increase the appeal of an analogous approach, namely, a physical barrier that presumably "blocks" immigrants from entry into one's country.

Two studies tested this idea. Study 1 found social media posts expressing support for the border wall were more likely to contain inundation-metaphoric expressions than both posts that expressed anti-immigration sentiment but did not mention the border wall and posts that expressed anti-border wall sentiment. These results suggest a positive association between use of the inundation metaphor and border wall support is present in everyday communication. Studies 2a and 2b found a causal link, showing, after controlling for political attitudes, exposure to the inundation metaphor led to greater support for the border wall than did reading about immigrants in literal terms.

The multimethod approach adopted in the present work provides novel insights into both the naturalistic use of metaphor in daily discourse as well as its causal impact. Interestingly, this impact was found to transcend political ideology. Previous research indicates metaphor framing effects are more potent when they support prior attitudes and help people reach desired conclusions (Landau et al., 2014). This previous work raises the possibility that using an inundation metaphor would be especially likely to foster border wall support for those with conservative political beliefs. Yet Study 2 found no indication of moderation by pre-existing political ideology, suggesting the capacity for the metaphor to promote metaphor-consistent attitudes is not an artifact of political orientation. Perhaps in the context in which the study was run, the metaphor was of sufficient cultural salience to be effective regardless of political orientation. Of course, Study 2 was not designed to test this interaction, and thus interpretation should be considered with caution until further research can be conducted.

The present findings also invite consideration of to what extent peripheral knowledge and general issue salience play a role in the use and power of metaphor. Consider, for example, that the present context is one in which the metaphor would seem, literally, to be a poor fit. The states that are predominantly adjacent to Mexico-Texas, New Mexico, and Arizona-are generally associated with tumbleweeds, cacti, and desert much more so than water. Yet the source knowledge associated with inundation (i.e., how to block waves and tides) is apparently potent enough to transfer to this rather arid geographical target. Future research might thus examine how such peripheral knowledge facilitates or undermines metaphor use. To what extent might an inundation metaphor impact support for structural restriction on immigration (i.e., border walls) outside the U.S.? Much public attention has been paid to refugees from Africa and the Middle East crossing the Mediterranean to arrive in Europe. Such sea arrivals are likely to invite inundation metaphor usage. However, further research is also needed to understand how these metaphors will influence attitudes toward immigrants in contexts that lack the border wall salience of the U.S. 
Study 1 is the first examination of conceptual metaphor on social media. This methodological approach offers unique insights into the process and consequences of metaphor usage. Specifically, it seems, in addition to metaphor exposure affecting political and social attitudes, people's organic use of metaphor reflects these attitudes. Further, social media analysis affords a look into metaphor usage in the real-world, an effort that complements qualitative methodologies that highlight this important component of metaphor studies.

These studies are not without limitation. That support for Trump and political conservatism differed between conditions in Study $2 \mathrm{~b}$ limited inferences about the effect size of the experimental manipulation. Further, as noted above, these studies do not inform whether the increased support for a border wall following exposure to the inundation metaphor would occur without the public salience of the border wall. Studies $2 \mathrm{a}$ and $2 \mathrm{~b}$ were conducted in early 2019, when the border wall dominated national political discourse. It remains unknown whether this effect would be observed when less attention was being paid to the border wall, or if a border wall was not already proposed and in construction. An additional limitation stems from the fact that the effects of Studies 2a and 2b were relatively small, emerging only after controlling for political attitudes. We do not claim that the inundation metaphor is the sole factor motivating border wall support, rather it is one contributing influence likely interwoven with dispositional political and personality attitudes. Although it is possible that repeated exposure to the inundation metaphor may have lasting effects, the present study cannot inform this potentiality. Finally, the present studies cannot inform whether the inundation metaphor motivates border wall support specifically, or immigration reduction strategies more broadly. In Study 1, inundation metaphor usage was more common among tweets supporting the border wall than among those supporting deportations of immigrants. Still, deportation concerns immigrants who are already in the country, rather than those yet to arrive. Inundation metaphor may motivate support for measures aimed at curbing immigration, such as restricting immigration visas. As the present studies were not designed to test this possibility, it cannot be ruled out without further empirical work. Still, given the above limitations, the present studies provide preliminary evidence of a connection between inundation metaphor and border wall support.

The present studies use observational and experimental methodologies to examine the relationship between inundation metaphor of immigration and border wall attitudes. Through Study 1's examination of tweets we see how inundation metaphor can be used naturalistically in everyday discourse. This is an important strength, yet this approach comes with inherent causal ambiguity. Study 2 addresses this limitation in showing experimentally manipulating exposure to an inundation metaphor, when accounting for existing political beliefs, increases support for a border wall. Taken together, the present work offers insights into the role of metaphor in how people understand immigration, and complex political issues more broadly, and the implications for consequent policy attitudes.

Funding: The authors have no funding to report.

Acknowledgments: The authors have no support to report.

Competing Interests: The authors have declared that no competing interests exist.

Data Availability: For this article, a dataset is freely available (Jimenez, Arndt, \& Landau, 2021).

\section{Supplementary Materials}

All study materials, coding details, and deidentified data can be found on the Open Science Framework (for unrestricted access see Index of Supplementary Materials below).

\section{Index of Supplementary Materials}

Jimenez, T., Arndt, J., \& Landau, M. J. (2021). Supplementary materials to "Walls block waves: Usage of and exposure to the inundation metaphor of immigration predicts support for a border wall" [Research data, codebook, and materials]. OSF. https://osf.io/c6afh 


\section{References}

Ainsley, J. (2019, June 5). Record number of undocumented immigrants flooded the southern border in May. NBC News. https:/www.nbcnews.com/politics/immigration/record-number-undocumented-immigrants-flooded-southern-border-mayn1014186

Baker, P. (2019, February 15). Trump declares a national emergency, and provokes a constitutional clash. The New York Times. https://www.nytimes.com/2019/02/15/us/politics/national-emergency-trump.html

Barends, A. J., \& de Vries, R. E. (2019). Noncompliant responding: Comparing exclusion criteria in MTurk personality research to improve data quality. Personality and Individual Differences, 143, 84-89. https://doi.org/10.1016/j.paid.2019.02.015

Böke, K. (1997). Die 'Invasion' aus den 'Armenhäusern Europas' [The 'invasion' from 'Europe’s poorhouses']. In M. Jung, M. Wengeler, \& M. Böke (Eds.), Die Sprache des Migrationsdiskurses: Das Reden über 'Ausländer' in Medien, Politik und Alltag (pp. 164-193). Opladen, Germany: Westdeutscher Verlag.

Burgers, C., Konijn, E. A., \& Steen, G. J. (2016). Figurative framing: Shaping public discourse through metaphor, hyperbole, and irony. Communication Theory, 26, 410-430. https://doi.org/10.1111/comt.12096

Cavazos-Rehg, P. A., Krauss, M. J., Costello, S. J., Kaiser, N., Cahn, E. S., Fitzsimmons-Craft, E. E., \& Wilfley, D. E. (2019). "I just want to be skinny": A content analysis of tweets expressing eating disorder symptoms. PLoS One, 14, Article e0207506. https://doi.org/10.1371/journal.pone.0207506

Charteris-Black, J. (2011). Politicians and rhetoric: The persuasive power of metaphor. London, United Kingdom: Palgrave Macmillan UK.

Charteris-Black, J. (2006). Britain as a container: Immigration metaphors in the 2005 election campaign. Discourse \& Society, 17, 563-581. https://doi.org/10.1177/0957926506066345

Chmielewski, M., \& Kucker, S. C. (2020). An MTurk Crisis? Shifts in data quality and the impact on study results. Social Psychological \& Personality Science, 11, 464-473. https://doi.org/10.1177/1948550619875149

Coulson, S. (2006). Semantic leaps: Frame-shifting and conceptual blending in meaning construction. Cambridge, United Kingdom: Cambridge University Press.

Crowne, D. P., \& Marlowe, D. (1960). A new scale of social desirability independent of psychopathology. Fournal of Consulting Psychology, 24, 349-354. https://doi.org/10.1037/h0047358

El Refaie, E. E. (2001). Metaphors we discriminate by: Naturalized themes in Austrian newspaper articles about asylum seekers. fournal of Sociolinguistics, 5, 352-371. https://doi.org/10.1111/1467-9481.00154

Gelfand, M., \& McCusker, C. (2002). Metaphor and the cultural construction of negotiation: A paradigm for theory and research. In M. Gannon \& K. L. Newman (Eds.), Handbook of cross-cultural management (pp. 292-314). New York, NY, USA: Blackwell.

Grover, T., Bayraktaroglu, E., Mark, G., \& Rho, E. H. R. (2019). Moral and affective differences in U.S. immigration policy debate on Twitter. Computer Supported Cooperative Work, 28, 317-355. https://doi.org/10.1007/s10606-019-09357-w

Hanne, M., Crano, W. D., \& Mio, J. S. (2014). Warring with words: Narrative and metaphor in politics. New York, NY, USA: Psychology Press.

Kearney, M. W. (2016). rtweet: Collecting Twitter data [Computer software]. Comprehensive R Archive Network.

Keefer, L. A., \& Landau, M. J. (2016). Metaphor and analogy in everyday problem solving. Wiley Interdisciplinary Reviews: Cognitive Science, 7, 394-405. https://doi.org/10.1002/wcs.1407

Keefer, L. A., Landau, M. J., Sullivan, D., \& Rothschild, Z. K. (2014). Embodied metaphor and abstract problem solving: Testing a metaphoric fit hypothesis in the health domain. fournal of Experimental Social Psychology, 55, 12-20.

https://doi.org/10.1016/j.jesp.2014.05.012

Koller, V. (2004). Metaphor and gender in business media discourse: A critical cognitive study. New York, NY, USA: Palgrave Macmillan.

Kruglanski, A. W., Crenshaw, M., Post, J. M., \& Victoroff, J. (2007). What should this fight be called? Metaphors of counterterrorism and their implications. Psychological Science in the Public Interest, 8, 97-133. https://doi.org/10.1111/j.1539-6053.2008.00035.x

Lakoff, G. (1991). Metaphor and war: The metaphor system used to justify war in the Gulf. Peace Research, 23(2-3), 25-32.

Lakoff, G., \& Johnson, M. (1980). Metaphors we live by. Chicago, IL, USA: University of Chicago Press.

Landau, M. J. (2017). Conceptual metaphor in social psychology: The poetics of everyday life. New York, NY, USA: Routledge.

Landau, M. J., Keefer, L. A., \& Rothschild, Z. K. (2014). Epistemic motives moderate the effect of metaphoric framing on attitudes.

Journal of Experimental Social Psychology, 53, 125-138. https://doi.org/10.1016/j.jesp.2014.03.009 
Landau, M. J., Meier, B. P., \& Keefer, L. A. (2010). A metaphor-enriched social cognition. Psychological Bulletin, 136, $1045-1067$. https://doi.org/10.1037/a0020970

Lederer, J. (2013). 'Anchor baby': A conceptual explanation for pejoration. Journal of Pragmatics, 57, 248-266. https://doi.org/10.1016/j.pragma.2013.08.007

Lee, K., Palsetia, D., Narayanan, R., Patwary, M. M. A., Agrawal, A., \& Choudhary, A. (2011). Twitter trending topic classification. In 2011 IEEE 11th International Conference on Data Mining Workshops: Conference proceedings (pp. 251-258). https://doi.org/10.1109/ICDMW.2011.171

Litman, L., \& Robinson, J. (2020). Conducting online research on Amazon Mechanical Turk and beyond. Thousand Oaks, CA, USA: SAGE.

Litman, L., Robinson, J., \& Abberbock, T. (2017). TurkPrime.com: A versatile crowdsourcing data acquisition platform for the behavioral sciences. Behavior Research Methods, 49, 433-442. https://doi.org/10.3758/s13428-016-0727-z

Musolff, A., \& Zinken, J. (Eds.). (2009). Metaphor and discourse. Basingstoke, United Kingdom: Palgrave Macmillan.

O’Brien, G. V. (2003). Indigestible food, conquering hordes, and waste materials: Metaphors of immigrants and the early immigration restriction debate in the United States. Metaphor and Symbol, 18, 33-47. https://doi.org/10.1207/S15327868MS1801_3

Pennebaker, J. W., Booth, R. J., \& Francis, M. E. (2007). Linguistic Inquiry and Word Count: LIWC [Computer software]. https://LIWC.net

Santa Ana, O. (1999). 'Like an animal I was treated': Anti-immigrant metaphor in US public discourse. Discourse \& Society, 10, $191-224$. https://doi.org/10.1177/0957926599010002004

Strom, M., \& Alcock, E. (2017). Floods, waves, and surges: The representation of Latin@ immigrant children in the United States mainstream media. Critical Discourse Studies, 14, 440-457. https://doi.org/10.1080/17405904.2017.1284137

Thibodeau, P. H., \& Boroditsky, L. (2011). Metaphors we think with: The role of metaphor in reasoning. PLoS One, 6, Article e16782. https://doi.org/10.1371/journal.pone.0016782

Thibodeau, P. H., Hendricks, R. K., \& Boroditsky, L. (2017). How linguistic metaphor scaffolds reasoning. Trends in Cognitive Sciences, 21, 852-863. https://doi.org/10.1016/j.tics.2017.07.001

Thibodeau, P. H., Matlock, T., \& Flusberg, S. J. (2019). The role of metaphor in communication and thought. Language and Linguistics Compass, 13, Article e12327. https://doi.org/10.1111/lnc3.12327

\section{Appendices}

\section{Appendix A: Inundation-Metaphoric Terms Included in Dictionary (Study 1)}

$\begin{array}{lc}\text { Wave } & \text { Floodgates } \\ \text { Flood } & \text { Floodgate } \\ \text { Flow } & \text { Flooded } \\ \text { Surge } & \text { Flowing } \\ \text { Tide } & \text { Overflow } \\ \text { Flooding } & \text { Overflowing }\end{array}$




\section{Appendix B: Immigration Framings (Studies 2a and 2b)}

\section{Inundation-Metaphoric Immigration Framing}

The United States has a problem with illegal immigration. Illegal immigrants flood into our nation and drown out the native population. Like water that runs downstream and settles at the lowest point, immigrants flow into unprotected areas. The United States' economy has not recovered from the 2008 recession. The unemployment rate is approximately $5 \%$, with an estimated 6 million working-age Americans out of a job. Many Americans believe illegal immigrants are taking their jobs and driving wages down. This economic turmoil has inspired the growing push for a border wall that separates the United States from Mexico to act as a levee against the incoming floodwaters. We simply do not have enough economic opportunities to sustain the cascade of workers that are pouring into our country. Furthermore, a significant percentage of illegal immigrants end up diverting a portion of their earnings back to their family members in Mexico rather than spending that money in the United States and stimulating our own economy. We have to block this wave of immigrants in order to protect our nation's interests and citizens.

\section{Literal Immigration Framing}

The United States has a problem with illegal immigration. Illegal immigrants come into our nation and displace the native population. Immigrants look for weaknesses and vulnerabilities, and settle in unprotected areas. The United States economy has not recovered from the 2008 recession. The unemployment rate is approximately 5\%, with an estimated 6 million working-age Americans out of a job. Many Americans believe illegal immigrants are taking their jobs and driving wages down. The economic turmoil has inspired a growing push for a border wall that separates the United States from Mexico to act as a barrier against the incoming immigrants. We simply do not have enough economic opportunities to sustain the mass of workers that are coming into our country. Furthermore, a significant percentage of illegal immigrants end up sending a portion of their earnings back to their families in Mexico rather than spending that money in the United States and stimulating our own economy. We have to block this migration in order to protect our nation's interests and citizens. 